\title{
Teses sobre hepatites na Faculdade de Medicina da Universidade Federal do Rio de Janeiro, 1837-2000
}

\author{
Theses on hepatitis at the Faculdade de Medicina of the \\ Universidade Federal do Rio de Janeiro, 1837-2000
}

\author{
Rosangela Gaze \\ Professora e pesquisadora do \\ Laboratório de História, Saúde e \\ Sociedade/Faculdade de Medicina \\ da Universidade Federal do Rio de \\ Janeiro (UFRJ). \\ Rua Teodoro da Silva, 751, bl. 2/504 \\ 20560-000 - Rio de Janeiro - RJ - \\ Brasil \\ rosangelagaze@gmail.com
}

\section{Diana Maul de Carvalho}

Professora e pesquisadora do Laboratório de História, Saúde e Sociedade/Faculdade de Medicina da UFRJ.

Rua Prof. Ortiz Monteiro, 88/303

22245-100 - Rio de Janeiro - RJ Brasil

dianamaul@medicina.ufrj.br

\section{Luiz Fernando Rangel Tura}

Professor e pesquisador do Laboratório de História, Saúde e Sociedade/Faculdade de Medicina da UFRJ.

Rua Belizário Távora, 211/304

22245-070 - Rio de Janeiro - RJ Brasil

luiztura@gmail.com

\section{Carolina Passos Telles Taveira Martins \\ Graduanda da Faculdade de Medicina da Universidade Federal da UFRJ. \\ Rua Prof. Gastão Bahiana, 114/204 22071-030 - Rio de Janeiro - RJ - Brasil \\ carolina_martins@hotmail.com}

\section{Vanessa Maria Tavares Lobato}

Graduanda da Faculdade de Medicina da UFRJ.

Rua Prof. Miguel Couto, 322/601 24230-240 - Niterói - RJ - Brasil lobatov@gmail.com
GAZE, Rosangela et al. Teses sobre hepatites na Faculdade de Medicina da Universidade Federal do Rio de Janeiro (1837-2000). História, Ciências, Saúde - Manguinhos, Rio de Janeiro, v.19, n.2, abr.-jun. 2012, p.541-561.

\section{Resumo}

Apresenta inventário das teses sobre hepatites da Faculdade de Medicina da Universidade Federal do Rio de Janeiro entre 1837 e 2000. A análise indica potencialidades e limites para discussão do quadro evolutivo do conhecimento científico no Brasil sobre esses agravos. As teses também são discutidas à luz de seus referenciais científicos e das mudanças tecnológicas e sociais que as influenciaram. Identificam-se e categorizam-se os marcos do ensino médico e do conhecimento sobre as hepatites, considerando que as teses revelam, no mínimo, o estado da arte de seu objeto. $\mathrm{O}$ estudo permitiu explorar as bases em que os saberes científicos sobre as hepatites foram construídos e indicar possibilidades de pesquisas na reconstrução do conhecimento científico de outros agravos.

Palavras-chave: hepatites; teses; história; ensino médico; Brasil.

\section{Abstract}

An inventory of the theses on hepatitis of the Faculdade de Medicina of the Universidade Federal do Rio de Janeiro between 1837 and 2000 is presented. The analysis indicates the potential and limits for discussion of the evolutionary framework of scientific knowledge on these health problems in Brazil. The theories are also discussed in light of their scientific reference points and the technological and social changes that influenced them. The landmarks in medical education and knowledge about hepatitis are identified and categorized, considering that the theses reveal at the very least the state of the art on the subject. The study makes it possible to explore the foundations upon which the scientific knowledge on hepatitis were built and indicate possibilities for research in the reconstruction of scientific knowledge of other health problems.

Keywords: hepatitis; theses; history; medical teaching; Brazil. 
$\mathrm{N}^{-1}$ este artigo indicamos algumas possíveis abordagens das teses sobre hepatites da Faculdade de Medicina da Universidade Federal do Rio de Janeiro (UFRJ), apresentadas no período de 1837 a 2000, com resgate dos marcos históricos que influenciaram o conhecimento científico, o diagnóstico e a classificação desses agravos (Andrade, 2003), tendo como pressuposto a importância dessa instituição na produção do conhecimento em ciências da saúde no Brasil (Mattoso, 1891; Roncaglio, Neuert, Martins, 2001; Espírito Santo, JacóVilela, Ferreri, 2006).

O estabelecimento do ensino médico no Rio de Janeiro é assunto controverso. Fernando Magalhães (1932) e outros estudiosos referem-se ao decreto de 5 de novembro de 1808, que criaria a Escola Anatômica, Médico-cirúrgica do Rio de Janeiro, como primeiro marco regulatório desse ensino, mas o decreto hoje não é encontrado. Lycurgo dos Santos Filho (1991) desconsidera a existência desse decreto e fixa o começo do ensino médico no Rio de Janeiro em 2 de abril de 1808, data da contratação do primeiro professor de anatomia para inaugurar os cursos no Hospital Militar do Morro do Castelo.

Em 1813, reorganizou-se o ensino médico no Brasil e instituiu-se a Academia Médicocirúrgica do Rio de Janeiro. Do período inicial, antes de 1813, parece haver pouca documentação que ateste a regularidade do curso e a organização disciplinar. Já quanto ao período posterior a esse ano, por meio dos livros de registro de alunos é possível constatar a regularidade do curso (Academia Médico-cirúrgica..., 1815-1819). ${ }^{1}$ No entanto, as fontes registram deficiências nessa formação, as quais motivaram, na década de 1820, a apresentação de projetos à Assembleia Legislativa, para reorganizar o ensino médico no Brasil.

Em 8 de outubro de 1830 a Câmara dos Deputados do Império solicitou à Sociedade de Medicina do Rio de Janeiro um projeto para a melhora do ensino nas escolas do Rio de Janeiro e da Bahia. A Sociedade elaborou o "Plano de organização das escolas médicas do Império", apresentado aos parlamentares pelo diretor Cruz Jobim. ${ }^{2}$ Desse plano derivou a lei de 3 de outubro de 1832, pela qual as academias passavam a ser denominadas faculdades de medicina. Conforme determinava o primeiro artigo da lei, as faculdades passavam a expedir o diploma de doutor em medicina, com o qual se poderia exercer, em todo o Império, qualquer dos ramos da arte de curar (Maia, 2010). O curso médico-cirúrgico era de seis anos, prevendo-se também um curso de farmácia com duração de três anos e um curso de partos.

Passava a caber às faculdades a revalidação dos títulos de médico, cirurgião, boticário e parteira obtidos no exterior, e não era mais concedido o diploma de sangrador. Novas exigências faziam parte dos exames de ingresso, como o conhecimento de latim e inglês ou francês, filosofia racional e moral, aritmética e geometria. Exigia-se a idade mínima de 16 anos completos para admissão ao curso e atestado de bons costumes emitido pelo juiz de paz da freguesia. $^{3}$

O curso médico era constituído de aulas teóricas e lições práticas nas enfermarias da Santa Casa de Misericórdia. As disciplinas incluíam física médica, química médica, mineralogia, zoologia, anatomia geral e descritiva, anatomia topográfica, fisiologia, farmácia, matéria médica, terapêutica e arte de formular, patologia externa, patologia interna, medicina operatória e aparelhos, partos, moléstias de mulheres pejadas e paridas e de meninos 
recém-nascidos, higiene, história da medicina e medicina legal (Maia, 2010). Com a organização da biblioteca da Faculdade, passaram a ser a ela incorporadas as teses, trabalhos obrigatoriamente apresentados, a partir de 1832, como requisito para obtenção do grau de doutor em medicina (Maia, Carvalho, 2008).

Em 1937 a Faculdade de Medicina do Rio de Janeiro (FMRJ) passou a denominar-se Faculdade Nacional de Medicina da Universidade do Brasil. Com a reforma iniciada em 1965, tomou a designação atual de Faculdade de Medicina da Universidade Federal do Rio de Janeiro e foi incorporada ao recém-criado Centro de Ciências da Saúde (CCS) (Favero, 2000). A referida biblioteca foi extinta, e o acervo, integrado ao de outras unidades na Biblioteca Central do CCS - principal depositária do corpus por nós inventariado.

Neste artigo, apresentamos o processo de identificação das fontes e sua descrição de acordo com os marcos do conhecimento científico acerca das hepatites. A periodização baseia-se na mudança de definição do documento denominado tese. Foram assim definidos três períodos: 1837-1930, 1931-1970 e 1971-2000. O primeiro merece discussão maior, em razão de singularidades ainda pouco exploradas por outros autores. As teses são analisadas com o fim de identificar as transformações na concepção teórica sobre o processo de determinação das hepatites, sua natureza e etiologia, e os marcos tecnológicos que influenciaram o diagnóstico e as mudanças classificatórias.

\section{O corpus documental}

Para identificar a produção relativa às hepatites nas teses e dissertações (TD) na Base Minerva da UFRJ, foram selecionados os descritores hepatite, fígado, icterícia e cirrose, com base nos seguintes critérios:

- hepatite: além de ser o termo corrente, era utilizado para um conjunto de hepatopatias e de sinais e sintomas classificados como hepatite durante todo o período estudado;

- fígado: principal órgão-alvo desse conjunto de patologias;

- icterícia: sinal mais frequentemente associado a hepatopatias, desde a Antiguidade;

- cirrose: alteração anatomofisiopatológica do fígado decorrente muitas vezes de uma hepatite; classificada entre as hepatopatias desde o século XIX (Guadagni, 1863), continua empregada até os dias atuais.

O levantamento na Base Minerva iniciou-se em 2007. Estabeleceu-se 2000 como limite da pesquisa por ser esse o último ano para o qual a base dispunha de um número representativo de teses. Após um pré-teste com as palavras selecionadas, empreendeu-se a pesquisa das teses na base utilizando-se opções de busca que ampliassem sua abrangência. Uma filtragem posterior, com exclusão de documentos, foi efetuada nas seguintes situações: TD de outras faculdades; teses cujos temas se referiam a medicamentos preparados com fígado e à pesquisa de doenças hepáticas em animais não relacionadas à segunda fase de ensaios clínicos; teses em duplicata na base, em virtude de terem sido indexadas por mais de um dos descritores selecionados. Excepcionalmente, permaneceram no corpus analisado teses baseadas em estudos experimentais em animais, em razão de sua relevante contribuição 
em termos de revisão bibliográfica sobre a história ou estado da arte do conhecimento sobre as hepatites. Ressalte-se que a busca por descritores se refere apenas àquelas teses que contêm as palavras-chave em seu título. Não há ainda, nessa base, sistema de busca que permita acesso ao texto completo.

Fisicamente, as teses estão organizadas como conjuntos encadernados ou documentos individuais. As TD do período 1837-1930 - datilografadas ou impressas - estão encadernadas em volumes, por ano de produção. Cada volume apresenta, na página inicial ou, mais raramente, na final, a lista das teses ali reunidas por ordem alfabética do sobrenome do autor, constando os itens autor, título e ano. As dissertações de mestrado e as teses de doutorado, livre-docência e concurso docente datadas de 1930 em diante estão conservadas, em sua maioria, em edições individuais. Esses documentos podem ser consultados na Seção de Teses da Biblioteca do CCS; para o acesso, é necessária solicitação prévia de acordo com as instruções disponíveis na página eletrônica.

No Rio de Janeiro, a biblioteca da Academia Nacional de Medicina (ANM) também possui exemplares das teses referentes ao período 1837-1930, encadernadas por ano e ordem alfabética de nome ou sobrenome do autor. A consulta pode ser efetuada pelo próprio pesquisador, no local. Exemplares das teses da FMRJ também estão disponíveis na Biblioteca Nacional (BN). Optamos por concentrar nossa pesquisa nas bibliotecas do CCS e da ANM.

O acesso às fontes depende das condições de preservação do acervo (Fonseca, 1995). Em relação às teses e dissertações da UFRJ (TDUFRJ), algumas se encontravam em adiantado estado de deterioração. Porém, com o auxílio de câmeras digitais com adequada resolução pudemos ler aquelas cujos manuseio e produção de cópias xerográficas não eram permitidos. As bibliotecas consultadas condicionaram a permissão para registro fotográfico à cessão de cópias do material, para compor seu acervo digital.

O tempo não é a única variável que contribui para o desgaste dessas fontes, visto que materiais por vezes recentes estão mais deteriorados que antigos. O tipo de papel, o cuidado no manuseio, a exposição ao calor e à umidade, o modo de arquivamento nas prateleiras, entre outros, são fatores conhecidos de conservação dos documentos. Vale registrar que algumas TD das décadas de 1980-1990 mostravam páginas aderidas, possivelmente devido à estocagem sob pressão por longo período. Intervenções estão sendo realizadas para melhorar as condições do acervo, incluindo a sua digitalização.

A denominação utilizada no cadastramento da Base Minerva para a produção de TDUFRJ até 1930, em relação ao tipo de documento, é 'tese', sem que se especifique o objetivo da mesma (UFRJ, s.d.). Tal explicitação - "para obtenção do grau de Doutor em Medicina" consta da capa ou página de rosto do documento original, o que nos permitiu a adequada classificação das teses, conforme a Tabela 1.

$\mathrm{Na}$ análise das teses, procuramos detectar marcos do conhecimento científico acerca das hepatites, com a leitura de 56 das 87 TD do período 1837-1930, oito dos 15 títulos datados entre 1931 e 1970, e 28 das 60 TD defendidas entre 1970 e 2000. Destaque-se que não há registro de teses entre 1851 e 1860, nessa base; outros fatores, além dos administrativos e das condições de conservação da documentação, talvez precisem ser considerados para entender tal lacuna. A primeira tese sobre hepatites registrada na base data de 1837. 
Tabela 1: Distribuição das teses e dissertações da UFRJ sobre hepatites, por tipo de documento Rio de Janeiro, 1837-2000

\begin{tabular}{lrr}
\hline Tipo de documento & № & \multicolumn{1}{c}{$\%$} \\
\hline Dissertação para obtenção do grau de doutor em medicina & 81 & 50,00 \\
Mestrado & 53 & 32,72 \\
Livre-docência & 15 & 9,26 \\
Doutorado & 10 & 6,17 \\
Tese de concurso docente & 5 & 3,09 \\
Exame de suficiência de médico para exercer a medicina no Brasil & 3 & 1,85 \\
\hline Total & $\mathbf{1 6 2}$ & $\mathbf{1 0 0 , 0 0}$ \\
\hline
\end{tabular}

Fontes: Base Minerva/UFRJ; teses e dissertações do acervo das Bibliotecas do CCS/UFRJ e da ANM.

Em termos da produção acadêmica, esses documentos podem ser subdivididos em três períodos:

- 1837-1930: os documentos designados como teses ${ }^{4}$ ou dissertações correspondem, na maioria, a trabalhos de conclusão de curso; denominados "Dissertações para obtenção do grau de Doutor em Medicina", eram requisitos obrigatórios no período 1832-1930 e neles se incluem as teses apresentadas para revalidação de diploma de médicos que concluíam o curso em outros países; constam também, nesse período, teses de concurso de cátedra e livre-docência;

- 1931-1970: as teses para obtenção do grau de doutor passam a ser produzidas de modo eletivo; há ainda algumas para revalidação de diplomas e as de concurso de livre-docência e professor catedrático ou titular (após 1965);

- 1971-2000: com o início dos programas de pós-graduação stricto sensu, em 1970, os documentos tomam a nomenclatura e forma atualmente utilizadas: dissertações de mestrado e teses de doutorado.

O conjunto documental analisado pode ser também considerado de acordo os modelos explicativos e métodos de diagnósticos das hepatites, sendo assim dividido nos seguintes períodos:

- 1837-1890: hegemonia do modelo fisiopatológico;

- 1891-1930: microrganismos como agentes etiológicos de doenças e discussão sobre a etiologia das icterícias;

- 1931-1960: achados histopatológicos de necrópsias e, posteriormente, de biópsias mostrando inflamação do parênquima hepático; identificação de dois possíveis agentes virais causadores de hepatites; e desenvolvimento de testes bioquímicos de necrose hepática (transaminases);

- 1960-1990: desenvolvimento de marcadores virais sorológicos; evolução à cronicidade; e hepatites não A não B (NANB);

- 1990-2000: desenvolvimento dos marcadores biomoleculares e emergência da hepatite C. 


\section{As “Dissertações para obtenção do grau de Doutor em Medicina”}

As teses do período 1837-1930 mostram, em sua maioria, discussão científica embasada na revisão da literatura. Barreto (1837), por exemplo, refere-se a Pinel para justificar a denominação hepatite à inflamação do fígado e Ferreira (1843) busca o Velho de Cós (Hipócrates) ao assinalar que a duração da hepatite variava de cinco a 15 dias. Para citar apenas algumas das referências aos autores mais citados, mencionamos Galeno, Claude Bernard, William Budd, Gilbert, Paul Erlich e Rokitansky. Não faltam alusões a autores brasileiros como Torres Homem, Miguel Couto, Rocha Faria e Garfield de Almeida. Além de informações relevantes acerca do referencial teórico dos graduandos em cada época, as TD mostram as referências dos docentes da própria FMRJ.

Quanto ao formato, a maior parte delas apresenta página de rosto com título do trabalho, instituição (Faculdade de Medicina do Rio de Janeiro), nome, naturalidade e filiação do autor, objetivo e data da apresentação e/ou defesa, referência da editora/tipografia e local. A segunda página, com a relação do corpo docente da FMRJ, pode ser aproveitada pelos interessados no estudo da estrutura acadêmica daquela faculdade ao longo do tempo (Figura 1).

No período em tela, todas as teses continham, no final, uma série de "Proposições" e "Aforismos de Hipócrates", e normas de apresentação do material. Essas proposições e máximas não são obrigatoriamente correlacionadas ao tema discutido na tese. A título de exemplo, citamos uma das proposições da tese de Lages Jr. (1874, p.41): "É no ato da inspiração que pode ter lugar a penetração de um corpo estranho na abertura superior do laringe". Gomes (1883, p.33), por sua vez, adicionou em sua tese sobre icterícia o seguinte aforismo: "Morbo regio laborantibus jecu durum fieri, malum (séc.IV)" (O aparecimento da icterícia, estando o fígado duro, é ruim).

Alguns autores deixam clara sua objeção ao fato de as TD serem um requisito obrigatório. Entre eles está Queiroz Jr. (1901), que critica não só essa obrigatoriedade como também a indicação do tema pela faculdade, revelando o estado de espírito com que muitas das teses foram redigidas no período. A indicação dos assuntos das teses pode contribuir para explicar a semelhança entre algumas, a exemplo da tese de concurso para a cadeira de fisiologia, de Francisco Pinheiro Guimarães (1871) e da dissertação de graduação de João Marinho Andrade (1883). De fato, várias TD versam sobre o mesmo tópico e frequentemente adotam o mesmo enfoque. Icterícia é o título ou o conteúdo principal, com pequenas variantes, de 17 teses entre 1837 e 1930. Três delas apresentam títulos idênticos: "Diagnóstico das causas mais comuns de icterícia crônica" (Lima, 1911; Meyer, 1913; Barbosa, 1915). A de Lincoln de Paula Barbosa (1915) parece resenhar a de Sebastião Meyer (1913), mas limita-se a observar, em nota de rodapé, que a observação clínica descrita foi publicada naquela tese. Essa característica, presente em outros documentos, remete a reflexões mais recentes sobre autoria.

Entretanto, em diversos documentos transparece o esmero na elaboração, manifestado na preocupação em apresentar errata ou corrigenda, esquemas e fotos.

Uma singularidade de algumas TD é o destaque conferido ao nome do autor e sua filiação - compostos nas folhas de rosto em letras grandes e, por vezes, acima mesmo do título da tese -, a sugerir que o conteúdo do trabalho não era tão valorizado quanto a sua 
FACULDADE DE MEDICINA DO RIO DE JANEIRO

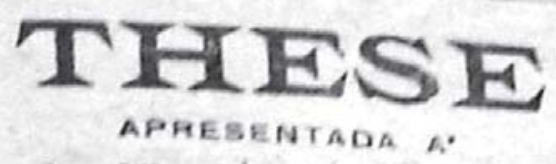

Faculdade de Medicina do Rio de Janeiro $\operatorname{zm} 9$ de Novembxo de 1920

- defendiaa em 20 de Dezembro do mesmo anno

$$
\text { pelo }
$$

DR. ALBERTO MIRANDA BAPTISTA DE OLIVEIRA

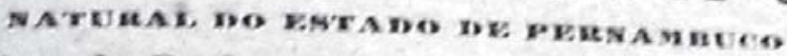

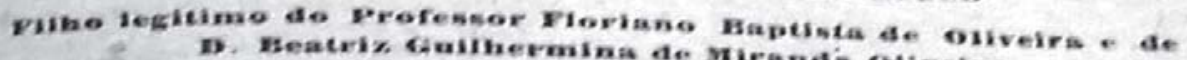

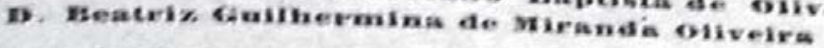

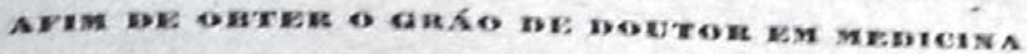

e.

\section{DISSERTAÇÃo}

\section{A NOVA CONCEPÇÃO DA ICTERICIA}

(Cadeira de Patholezia Geral)

Approvada plenamente

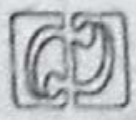

RIO DE JANEIFO

PAP, CONFIANOA

Andradas, $71-1920$

Figura 1: Tese de Alberto Miranda Baptista de Oliveira (1920) (Biblioteca Central do Centro de Ciências da Saúde/UFRJ) 
concretização em uma publicação (Figuras 2 e 3). Tal destaque gráfico sugere uma menor valorização do conteúdo do trabalho do que ao fato em si de sua concretização. Em algumas teses, o título sequer aparece na página de rosto (Figura 4).

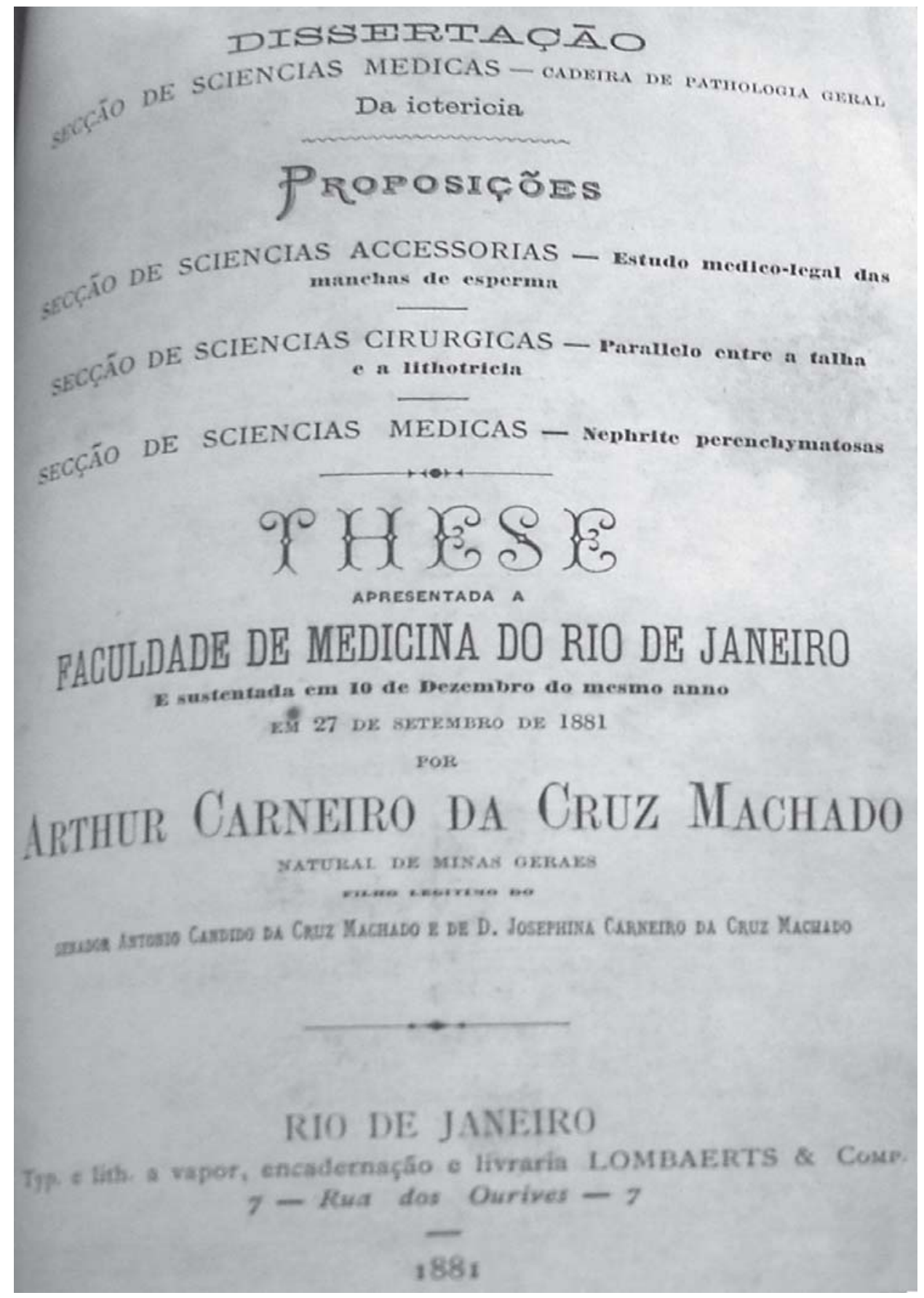

Figura 2: Tese de Arthur Carneiro da Cruz Machado (1881) (Biblioteca Central do Centro de Ciências da Saúde/UFRJ) 


\section{FACULDADE DE MEDICINA DO RIO DE JANEIRO}

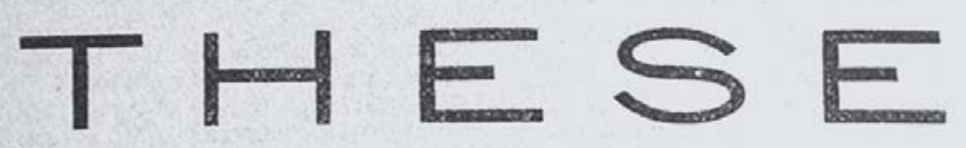

APRESENTADA Á

FACULDADE DE MEDICINA DO RIO DE JANEIRO EM 26 DE DEZEMBRO DE 1927

E DEFENDIDA EM 27 DE DEZEMBRO DE 1927

$$
\text { - POR - }
$$

\section{Mario Duque Estrada}

(Natural do Districto Federal)

Filho legitimo do

Dr. Henrique Dias Duque Estrada e D. Alice Faller Duque DISSERTAC̨ÃO :

\section{SUBSIDIO AO ESTUDO DAS ICTERICIAS}

(CADEIRA DE CLINICA MÉDICA)

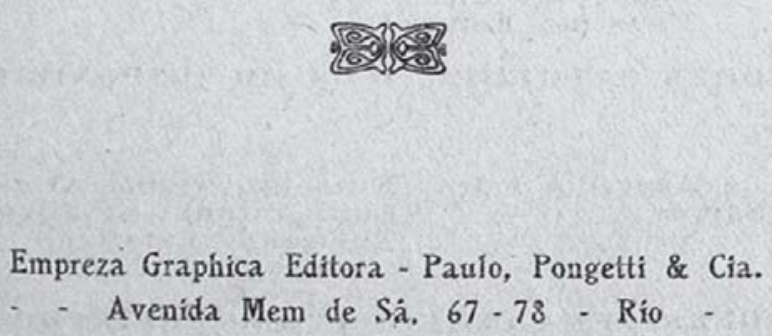

- Avenida Mem de Sá, $67-78$ - Rio -

Figura 3: Tese de Mario Duque Estrada (1927) (Biblioteca Central do Centro de Ciências da Saúde/UFRJ) 


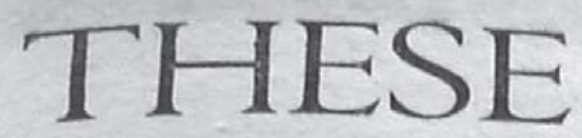

APRESENTADA A'

FACULDADE DE MEDICINA DO RIO DE JANEIRO

EM I9 DE SETEMBRO DE I $88 \mathrm{r}$

E SUSTENTADA PERANTE a MESMa FACULdAde

耳o die 1 de Dezembxo de 1881 PELO

Dr. Antonio Moreira da Silva Sobrinho

Natural de Itaguahy, provincia do Rio de Janeiro.

FILHo LIGITIMo Do

DR. JOAQUIM MOREIRA DA SILVA

E DE

D. MARIA DA GLORIA MOREIRA DA SILVA

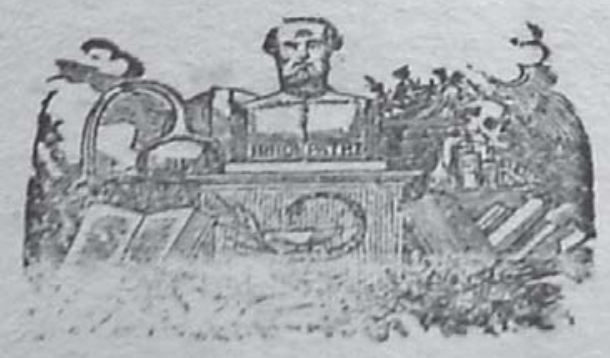

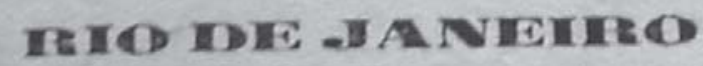

Tpp. Litteratia, rua Sete de Setembro n. 131

\section{1.}

Figura 4: Tese de Antonio Moreira da Silva Sobrinho (1881) (Biblioteca Central do Centro de Ciências da Saúde/ UFRJ) 
A partir do século XX, as teses começam a apresentar revisão da literatura sob a forma de lista de referências bibliográficas, tal como as da atual produção científica. A tese de Almeida (1910, p.45) é ilustrativa dessa característica, como também destaca a pluralidade de obras em outros idiomas acessíveis aos autores, ao referenciar estudos em francês, alemão e italiano, com predominância dos dois primeiros (Figura 5). É comum encontrar, nas teses até 1930, citações em francês incorporadas sem tradução ao texto. Nas posteriores permanecem as referências, mas os idiomas predominantes passam a ser o francês e o inglês e, mais recentemente, o inglês e o espanhol.

\section{BIBLIOGRAPHIA}

Fernnndes Figueira - Éléments de semeiologie infantile. 1903.

IR. Conchet e H. Seregé - L'évolution clinique du foie chez l'enfan normal.

Gazete hebdomudaire de sciences medicales de Bordearx- N. $14-1908$.

II. Danchez - Note sur quatre-vingt-huit mensurations comparatives du foie à l'état sain et à l'état pathologique chez l'enfant, aux differents âges.

Revue des maladies de l'enfance-Septembre, 1892.

Hermann Sahli - Die topographische Percussion im Kindesalter - 1882.

Massini Virginio - Fisiologia della infanzia e della fanciulleza-1886.

c. Gerhardt - Trattato delle malattie dei bambini-Vol. I, Parte I, 1887.

-. Heubner - Trattato delle malattie dei bambini-Vol. II, 1994.

Edoardo Henoch - Malattie dei bambini-Parte II, 1903.

Eallantyne - Introduction to the diseases of infancy, 1891.

Grancher et Comby - Maladies de l'enfance-Vo!. II, 1994.

v. Uusines - La pratique des maladies des enfants-Vol. III, 1909. 
Ao analisar a bibliografia dessas teses, e considerando que, na época, a Biblioteca da FMRJ era das poucas existentes, pode-se deduzir que os livros e artigos referidos integravam esse acervo - como provavelmente ainda hoje ocorre, por possuir a biblioteca uma das melhores coleções da área. Foi possível ainda identificar edições posteriores de livros em idiomas diferentes da edição original. Como exemplo, Fraga Filho (1952), ao discutir a etiologia da icterícia catarral, cita obras de Virchow (1874) em francês e de Eppinger (1940) em espanhol, cujos originais são em alemão. ${ }^{5}$

Um comentário final acerca dessas fontes. Alguns autores expressavam seu apreço pelo tema ou pela obra empregando metáforas que tornavam a dissertação mais do que o cumprimento de um dever, pois conferiam ao saber científico o caráter humano:

Mas ainda pode o fígado concentrar, em sua rede vascular, quantidade considerável de sangue; e, então, faz ele o ofício de uma caixa de previdência, de um reservatório que regulariza a circulação. Dificilmente se escapa, em analisando as funções hepáticas, à velha tentação teleológica. Quase se é levado a descortinar no fígado o órgão de uma mais profunda consciência: a consciência fisiológica. Dir-se-ia, com efeito, residir nele um senso análogo ao senso moral, dada a faculdade que se lhe atribui de fazer a distinção do bem e do mal, na ordem biológica, assim como ela é feita, na ordem social, pelas eminentes faculdades que têm por sede o cérebro (Miranda, 1910, p.18).

\section{O conhecimento científico sobre as hepatites e as teses da UFRJ6}

Constata-se maior concentração das TDUFRJ sobre hepatites em três períodos: 18811930 (77 títulos), 1951-1990 (33 títulos), e década de 1990 (39 títulos). O período de 1881 a 1930, com quase 50\% dessa produção e numa fase em que a apresentação de TD era obrigatória, situa-se na época em que o conhecimento científico sobre a determinação das doenças estava sendo revolucionado pelo surgimento da teoria microbiológica. Talvez isso explique o maior interesse dos formandos no assunto, ou pode sugerir também que a Faculdade indicava temas que pudessem explorar as mudanças de paradigma científico. Os marcos tecnocientíficos das hepatites estão indicados no Quadro 1.

Quadro 1: Marcos tecnocientíficos das hepatites ilustrados pelas TDUFRJ - Rio de Janeiro, 1837-2000

\begin{tabular}{|c|c|c|c|}
\hline Períodos & $\begin{array}{l}\text { Marcos } \\
\text { tecnocientíficos }\end{array}$ & $\begin{array}{l}\text { TDUFRJ } \\
\text { ilustrativas } \\
\text { dos marcos }\end{array}$ & Conteúdo \\
\hline \multirow[t]{4}{*}{1837 a 1890} & \multirow{4}{*}{$\begin{array}{l}\text { Hegemonia do } \\
\text { modelo fisiopatológico }\end{array}$} & Barreto, 1837; & Classificação das hepatites \\
\hline & & Ferreira, 1843 & $\begin{array}{l}\text { abrangendo diversas hepatopatias } \\
\text { (litíase biliar, cistos, tumores, cirrose } \\
\text { etc.) e causas (excessos alimentares, } \\
\text { sexuais, ocupacionais e terapêuticos, } \\
\text { cálculos biliares etc.) }\end{array}$ \\
\hline & & Guadagni, 1863 & Quadro clínico e tratamento da cirrose \\
\hline & & Lages Jr., 1874 & Valorização da história e exame clínico \\
\hline 1891 a 1930 & $\begin{array}{l}\text { Teoria microbiológica } \\
\text { Discussão sobre a } \\
\text { etiopatogenia das } \\
\text { icterícias }\end{array}$ & Queiroz Jr., 1901 & $\begin{array}{l}\text { Captação do momento da revolução } \\
\text { paradigmática de modelos explicativos } \\
\text { de doença pela descoberta da existência de } \\
\text { microrganismos. "Antissepsia e assepsia" } \\
\text { (p.27) }\end{array}$ \\
\hline
\end{tabular}


Quadro 1(cont.): Marcos tecnocientíficos das hepatites ilustrados pelas TDUFRJ - Rio de Janeiro, 1837-2000

\begin{tabular}{|c|c|c|c|}
\hline Períodos & $\begin{array}{l}\text { Marcos } \\
\text { tecnocientíficos }\end{array}$ & $\begin{array}{l}\text { TDUFRJ } \\
\text { ilustrativas } \\
\text { dos marcos }\end{array}$ & Conteúdo \\
\hline \multirow[t]{4}{*}{1891 a 1930} & \multirow{4}{*}{$\begin{array}{l}\text { Teoria microbiológica } \\
\text { Discussão sobre a } \\
\text { etiopatogenia das } \\
\text { icterícias }\end{array}$} & Lima, 1911 & $\begin{array}{l}\text { Dificuldade no diagnóstico } \\
\text { etiopatogênico das icterícias }\end{array}$ \\
\hline & & Pereira, 1916 & $\begin{array}{l}\text { Respeito ao paciente e à sua inserção } \\
\text { social }\end{array}$ \\
\hline & & Barbosa, 1921 & $\begin{array}{l}\text { Faceta relevante da polêmica sobre a } \\
\text { natureza da icterícia catarral (obstrutiva } \\
\text { x infecciosa) }\end{array}$ \\
\hline & & Estrada, 1927 & $\begin{array}{l}\text { Importância dos exames } \\
\text { complementares (resultados } \\
\text { laboratoriais, laudos de necrópsia e } \\
\text { histopatológicos, fotografias de } \\
\text { lâminas) }\end{array}$ \\
\hline \multirow[t]{5}{*}{1931 a 1960} & Necrópsias e biópsias & \multirow[t]{4}{*}{ Fraga Filho, 1952} & \multirow{4}{*}{$\begin{array}{l}\text { Resgate histórico (séc. XIX e XX) da } \\
\text { polêmica sobre a etiopatogenia da } \\
\text { icterícia (Virchow x Eppinger); registro } \\
\text { da "iatrogenia da medicina preventiva e } \\
\text { curativa" (p.21); crítica aos excessivos } \\
\text { experimentos in anima nobile e } \\
\text { quadros com listas dos experimentos } \\
\text { sobre hepatite infecciosa e } \\
\text { soro-homóloga }\end{array}$} \\
\hline & $\begin{array}{l}\text { Inflamação do } \\
\text { parênquima hepático }\end{array}$ & & \\
\hline & $\begin{array}{l}\text { Dois possíveis agentes } \\
\text { virais de hepatites }\end{array}$ & & \\
\hline & \multirow[t]{2}{*}{ Transaminases } & & \\
\hline & & Nery, 1959 & $\begin{array}{l}\text { Importância clínica do desenvolvimento } \\
\text { das transaminases }\end{array}$ \\
\hline \multirow[t]{9}{*}{1961 a 1990} & \multirow{2}{*}{$\begin{array}{l}\text { Marcadores virais } \\
\text { sorológicos }\end{array}$} & Fraga, 1974 & Hepatites crônicas \\
\hline & & Fonseca, 1976 & Hepatocarcinoma primitivo \\
\hline & \multirow{7}{*}{$\begin{array}{l}\text { Hepatites crônicas } \\
\text { Hepatites NANB }\end{array}$} & Morgado, 1975 & Hepatite por imunoglobulina e \\
\hline & & & $\begin{array}{l}\text { referencia de surto de hepatıte } \\
\text { pós-vacinação antiamarílica }\end{array}$ \\
\hline & & Coelho, 1981 & $\begin{array}{l}\text { Estado da arte do diagnóstico e } \\
\text { tratamento das hepatites crônicas }\end{array}$ \\
\hline & & Toledo, 1984 & 'Emergência' das hepatites NANB \\
\hline & & Gonçalves, 1987 & $\begin{array}{l}\text { Atualização da situação epidemiológica } \\
\text { da infecção pelo VHB entre doadores } \\
\text { de sangue }\end{array}$ \\
\hline & & Mello, 1988 & $\begin{array}{l}\text { Prevalência elevada do VHB entre } \\
\text { hemofílicos }\end{array}$ \\
\hline & & Soares, 1988 & $\begin{array}{l}\text { Hepatite pós-transfusional NANB na } \\
\text { cirurgia cardíaca }\end{array}$ \\
\hline \multirow[t]{3}{*}{1991 a 2000} & \multirow{3}{*}{$\begin{array}{l}\text { Marcadores } \\
\text { biomoleculares }\end{array}$} & Equi, 1995 & Hepatite por hemodiálise \\
\hline & & Rezende, 1997 & $\begin{array}{l}\text { Emergência da hepatite C } \\
\text { Genotipagem do VHC e } \\
\text { terapia antiviral }\end{array}$ \\
\hline & & $\begin{array}{l}\text { Carvalho, } 1992 \\
\text { Perez, } 1993 \\
\text { Garbes Netto,1994 } \\
\text { Leite, 1995 } \\
\text { Artemenko,1996 } \\
\text { Alvariz, 1997 } \\
\text { Basile, } 2000 \\
\text { Coelho, 1998 } \\
\text { Rozenbaum, } 1998 \\
\end{array}$ & Infecção pelo VHC \\
\hline
\end{tabular}

Fonte: Minerva/UFRJ e edições originais do acervo das bibliotecas do CCS/UFRJ e ANM. 
Da análise das teses pôde-se depreender que, na primeira metade do século XIX, a denominação hepatites abrangia diferentes diagnósticos etiológicos. As causas predisponentes compreendiam uma diversidade de fatores como bebidas e excessos alimentares, habitação em pântanos, paixões veementes e trabalhos excessivos - todos tornavam o comportamento bilioso. As causas determinantes, também múltiplas, incluíam traumas sobre o hipocôndrio direito, cálculos biliares, fraturas do crânio, excesso de vomitivos, abuso dos prazeres venéreos, repercussão de exantema, artrites, inflamação de hemorroidas e gota (Barreto, 1837; Ferreira, 1843).

Outra contribuição extraída desse corpus é a compreensão do modo como foram construídos, ao longo do tempo, conceitos e representações presentes hoje sobre as hepatites (Gaze, Carvalho, Tura, 2003; Espírito Santo, Jacó-Vilela, Ferreri, 2006) e, consequentemente, como se deu a possibilidade de questionar "leituras equivocadas de eventos de outras épocas" (Espírito Santo, Jacó-Vilela, Ferreri, 2006, p.19) na orientação de atuais condutas clínicas. Um exemplo é a orientação médica de repouso absoluto em casos de hepatite aguda, provavelmente resquício de uma prática datada do início do século XIX, quando se acreditava que um dos fatores predisponentes era o trabalho excessivo. Em 1952 Fraga Filho ainda assinalava o repouso como um dos recursos terapêuticos para a doença. Estudos publicados pouco depois já contestaram tal recomendação. O de Chalmers e colaboradores (1955), realizado durante a Guerra da Coreia, mostrava que soldados que retornaram ao combate após curto período de convalescença se recuperaram melhor do que aqueles submetidos a longo período de repouso no leito.

Identificar os marcos tecnológicos que transformaram o diagnóstico das hepatites e orientaram mudanças classificatórias possibilita reconstruir o processo pelo qual as diferentes hepatopatias foram especificadas e as hepatites de hoje, vistas como agravos diferenciados. Nesse corpus é possível acompanhar a ocorrência dessas mudanças e periodizá-las, considerando-se ainda as alterações de modelos explicativos e das chaves classificatórias que ocorrem quase simultaneamente. Observamos, por exemplo, que no período compreendido entre 1837 e 1890 o modelo fisiopatogênico de explicação de doenças predominava, e as teses concentravam-se na discussão da classificação das hepatopatias, entre elas as hepatites, com base no quadro anatomofisiopatológico. O uso da apurada semiótica clínica era fundamental ao diagnóstico, conforme reiterado na tese de Queiroz Jr. (1901).

É possível também captar o momento da revolução microbiana. O mesmo Queiroz Jr. (1901, p.29, 27, 21) expressa preocupação em evitar a contaminação, no tratamento cirúrgico da 'hepatite supurada'. Esse autor relata a divisão de opiniões entre os cientistas acerca do pus 'séptico' ou 'asséptico'; destaca o uso de culturas de estafilococos em batatas e descreve regras de 'antissepsia e assepsia' pré-cirúrgicas: "ensaboar o ventre, raspar os pelos, lavar com uma solução de sublimado, álcool, etc. Instrumental esterilizado na estufa ou, se não se tem estufa, fervido em uma solução de água fenicada...".

Barbosa (1921) apresenta em sua dissertação um aspecto significativo da polêmica sobre a natureza infecciosa ou obstrutiva da icterícia catarral, posteriormente reconhecida como uma hepatite viral. Ao abordar as limitações técnicas das necrópsias, redimensiona o valor inconteste da histopatologia nos séculos XIX e XX. Seu comentário sobre a investigação da etiologia das icterícias, praticamente restrita aos canais biliares, conduz à reflexão de 
que a formulação de múltiplas hipóteses e a sua comprovação/refutação mediante metodologia adequada é condição sine qua non para os avanços do conhecimento.

Característica marcante das teses produzidas até o final do Oitocentos é a valorização da história e o exame clínico dos pacientes - praticamente os únicos recursos diagnósticos disponíveis -, detalhados e sensíveis a ponto de possibilitar a diferenciação entre um cisto hidático e um abscesso hepático (Lages Jr., 1874). Sabendo-se que cistos e abscessos hepáticos têm conteúdo líquido e frequentemente são de etiologia parasitária, diferenciá-los clinicamente, sem métodos de imagem ou punção, é um desafio.

Por sua vez, Rodrigues Pereira (1916, p.39) deixa transparecer o respeito ao paciente e à sua inserção social em cuidadosa anamnese: "Sempre foi um homem trabalhador mas há uns quatro para cinco meses começou-lhe a diminuir o apetite, bem como o amor ao trabalho." Sob esse prisma, a leitura das TDUFRJ pode contribuir para a revalorização da relação médico/paciente, especialmente útil se incorporada ao ensino da graduação.

Ainda assim, a relevância dos exames complementares não era desprezada, como verificamos na tese de Mario Duque Estrada (1927), com observações clínicas baseadas em resultados laboratoriais, laudos de necrópsia e histopatológicos, inclusive com reprodução de fotografias de lâminas (Figura 6).

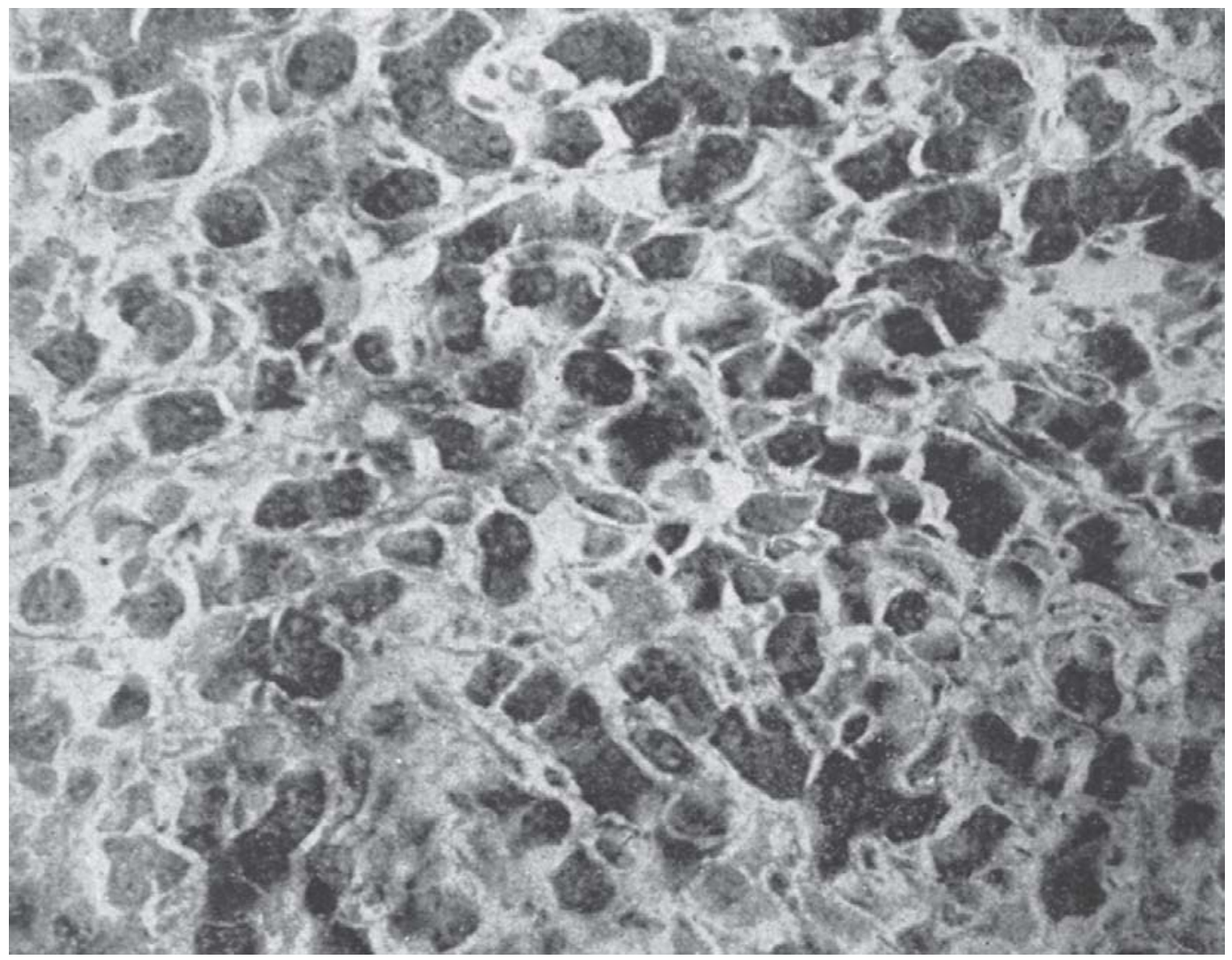

Figura 6: Fragmento de tecido hepático obtido por necrópsia, na tese de Mario Duque Estrada (1927) (Biblioteca Central do Centro de Ciências da Saúde/UFRJ) 
De 1931 a 1970, a produção relativa às hepatites sofre uma redução. Apenas 15 títulos estão registrados na Base Minerva, sendo seis teses e dissertações, sete teses de livre-docência e duas de concursos docentes. Entre 1931 e 1940, há quatro sobre outros assuntos, sendo apenas uma da FMRJ. Este período (1931-1970) marca a supressão da exigência das teses de final de curso e merece estudos mais detalhados. Desse período incluímos a discussão de oito dos documentos.

A tese de Clementino Fraga Filho (1952) é importante marco, porque traz implícita uma crítica aos excessivos experimentos in anima nobile e discute experimentos em humanos sobre a hepatite infecciosa e por soro-homólogo, como também a reprodutibilidade dos resultados. Seu trabalho permite conhecer o número de voluntários inoculados, os autores e os anos das pesquisas, fornecendo material adicional para discussões éticas sobre a necessidade desses repetidos estudos. Mostra ainda o estágio do conhecimento acerca dos mecanismos de transmissão das hepatites e seus diversos períodos de incubação.

Entre 1970 e 2000, período em que se inicia a produção de dissertações e teses de pósgraduação da Faculdade de Medicina, destacamos a dissertação de Anastácio Ferreira Morgado (1975), que possibilitou o reconhecimento da associação inequívoca de casos de hepatite B com o uso de gamaglobulina humana contaminada por trabalhadores de uma empresa distribuidora de medicamentos no Rio de Janeiro. Pela investigação epidemiológica, Morgado ratifica o ponto de vista de Fraga Filho (1952) sobre o caráter iatrogênico da hepatite B e cita artigos científicos com relatos de casos de hepatite no Rio de Janeiro pós-vacinação antiamarílica, investigados por Soper e Smith em 1938. Essa dissertação ilustra a relevância do estudo de teses acadêmicas para o resgate de informações sobre a ocorrência de surtos no Brasil, dos quais, muitas vezes, não são encontrados registros em outras fontes. Permite ainda discutir defasagens entre o conhecimento científico e a tomada de decisão política, a exemplo do lapso de trinta anos entre a identificação do vírus VHB e suas formas de transmissão e as ações de controle dessa infecção, ao passo que no caso do HIV o intervalo foi de três anos (Alter, 2008).

A propagação das hepatites, em especial as denominadas virais posteriormente, foi influenciada pelas 'mudanças tecnológicas', nelas incluídos procedimentos médico-cirúrgicos que visavam tanto ao tratamento de doenças como as hemotransfusões e hemodiálises (Fraga Filho, 1952; Morgado, 1975; AABB, s.d.; Equi, 1995) quanto à prevenção de outras, como as imunizações ativas e passivas (Lürman, 12. Jan. 1885; Fraga Filho, 1952; Morgado, 1975).

O uso intensivo da vacina contra a febre amarela durante a Segunda Guerra Mundial e o registro, no período de seis meses, de 28.585 casos de icterícia entre os combatentes (com 62 óbitos) suscitaram, na época, a hipótese de associação entre esses eventos (Jaundice following..., Aug. 1, 1942). Embora esses efeitos adversos tenham marcado a história da iatrogenia envolvendo vacinas, não foi possível examinar a influência que exerceram na escolha dos temas das TDUFRJ, visto que, entre 1930 e 1969, das 13 teses sobre hepatites registradas na Base Minerva, a única que trata dessa questão é a de Fraga Filho (1952).

A revisão bibliográfica de autores das TDUFRJ dos anos subsequentes (Fraga Filho, 1952; Morgado, 1975; Coelho, 1981, 1998) contribuiu para o resgate de relevante marco da história das hepatites virais: a designação de suas diversas etiologias por letras do alfabeto. 
Na seção de Medicina Geral de Discussões Científicas, na Conferência Internacional de Médicos ocorrida em Londres, em 11 de setembro de 1947, o doutor MacCallum propôs que o vírus que desencadeava a hepatite epidêmica fosse denominado vírus A da hepatite e o que causava a icterícia soro-homóloga, vírus B da hepatite (Infective hepatitis, Sept. 20, 1947). MacCallum (1972, p.108) explicita seus próprios passos na construção dessa nomenclatura: "Finalmente, sugeri (vide Lancet, 1947) que, de modo a evitar confusão, os dois vírus ou subtipos virais devam ser denominados vírus A, o que leva à hepatite infecciosa após um curto período de incubação (e, como o sangue é infectante, poderia em certo sentido ser denominada de hepatite sérica) e vírus B, que, após um longo período de incubação, origina a hepatite sérica" (tradução livre).

Benchimol (2001, p.206) discorre sobre a íntima relação da vacina antiamarílica e os surtos da doença atualmente reconhecida como hepatite B, trazendo à luz duas singularidades importantes. Uma é que os primeiros surtos de icterícia pós-vacinal foram observados em 1936-1937, quando soros hiperimunes de macacos eram utilizados como conservantes. A outra é que, embora o custo de produção da vacina fosse reduzido pela eliminação do 'soro humano normal' (responsável pela transmissão da hepatite) - o que possibilitava suprimir gastos com captação e triagem de doadores de sangue, coleta e controle da qualidade do soro obtido, bem como empregar maiores diluições com redução no volume das doses -, a suspensão do uso do soro humano como conservante só ocorreu após 1942.

Na década de 1990, a hepatite C ganhou destaque. Com a disponibilidade de marcador sorológico (Choo et al., Apr. 21, 1989) e portadores do HIV adoecendo ou morrendo por cirrose decorrente dessa coinfecção, cresceu o interesse em seu estudo. Na esteira dessa tendência, as dissertações e teses dos anos 1990 concentram-se na hepatite C - dos 39 documentos arrolados, 14 tratam da infecção pelo VHC. Outro aspecto da produção acadêmica do período relaciona-se ao enfoque metodológico, com predomínio de estudos epidemiológicos, talvez influenciados pelo momento histórico caracterizado pela identificação da volumosa fração de casos de hepatites NANB de transmissão parenteral e pelo desenvolvimento da epidemiologia clínica. A visibilidade crescente da doença foi também influenciada por fatores que não estão sendo aqui considerados, como os movimentos demográficos, a urbanização e as mudanças no mundo do trabalho, entre outros.

\section{Considerações finais}

Com base no acervo de teses e dissertações analisado, verifica-se a possibilidade de explorar aspectos pouco conhecidos do entendimento científico sobre as hepatites no Brasil, identificando-se as bases em que ele foi construído. Deve-se registrar que, se o direcionamento desses estudos foi influenciado pelos avanços tecnológicos, estes, igualmente, sofreram influência das pesquisas. À semelhança de Pimentel (2001, p.192), percebese que "a produção de ideias e saberes científicos tem um caráter eminentemente social", indissociável dos acontecimentos sociopolítico-culturais e econômicos de sua época (Fonseca, 2002). Direta ou indiretamente e com maior ou menor impacto, o aumento da 
sensibilidade e praticidade dos métodos diagnósticos, o conhecimento sobre a transmissão transfusional de hepatites, a detecção de elevadas prevalências das infecções e a disponibilidade de agentes antivirais construíram o saber científico e não científico sobre as hepatites virais. Trata-se de um saber que gera novos saberes e mobiliza pessoas e sistemas do complexo tecido social.

Hoje, dissertações e teses tendem a dar lugar a artigos científicos, que, menos extensos, favorecem a redução nos prazos de pesquisa no intuito de atingir indicadores e metas estabelecidos por sistemas avaliadores de programas de pós-graduação. A consolidação dessa tendência poderá levar à perda de fontes valiosas para a discussão da história da ciência - não mais pelo extravio e pela deterioração desses documentos, mas porque eles não mais serão produzidos.

\section{AGRADECIMENTOS}

A Michelle Soares da Silva (in memoriam), graduanda da Faculdade de Medicina da UFRJ, pela contribuição na leitura e no fichamento das fontes.

\section{NOTAS}

${ }^{1}$ O livro de matrículas de alunos da Academia Médico-cirúrgica do Rio de Janeiro relativo ao ano de 1815 encontra-se disponível em http://www.museuvirtual.medicina.ufrj.br/painel/arquivos_obras/ 15032006135626.pdf.

2 José Martins da Cruz Jobim (1802-1878), diretor da escola médica e deputado em seguidos mandatos, foi o diretor que mais tempo esteve no cargo e menos tempo exerceu de fato a direção da Academia (Magalhães, 1932).

${ }^{3}$ Essa exigência perdurou até, pelo menos, a década de 1940, conforme documentos constantes das pastas dos alunos, sob a guarda do Centro de Documentação do Ensino das Ciências da Saúde (Cedem)/ Centro de Ciências da Saúde (CCS)/UFRJ.

${ }^{4}$ A Base Minerva utiliza grafias variadas como tese e these, e não realiza busca de termos equivalentes.

${ }^{5}$ Essas edições não puderam ser localizadas, pois ao tomarmos conhecimento de sua existência o Setor de Obras Raras da Biblioteca do CCS estava em obras.

${ }^{6}$ Utilizamos aqui a denominação hepatites ainda que ela não seja de todo apropriada para o período considerado. Hepatopatias poderia ser mais adequado para algumas teses. Hepatite, no singular, não compreende o leque de doenças incluídas na complexa (e variável) nomenclatura desse grupo. Icterícia, sinal predominante de hepatites, diversas hepatopatias, doenças hemolíticas, obstruções biliares e infecções sistêmicas são termos que, além de pouco específicos, não designam hoje uma doença.

\section{REFERÊNCIAS}

AABB.

American Association of Blood Bank. Facts about blood and blood banking: highlights of transfusion Medicine History. Disponível em: http://www.aabb.org/resources/bct/Pages/ highlights.aspx. Acesso em: 31 out. 2010. s.d.

ACADEMIA MÉDICO-CIRÚRGICA...

Academia Médico-cirúrgica do Rio de Janeiro. Livro de matrículas. (Centro de Documentação do Ensino das Ciências da Saúde/Centro de
Ciências da Saúde/Universidade Federal do Rio de Janeiro). 1815-1819.

ALMEIDA, Cyro Werneck.

Contribuição para o estudo do fígado na infância. Dissertação para obtenção do grau de Doutor em Medicina - Faculdade de Medicina do Rio de Janeiro, Rio de Janeiro. 1910.

ALTER, H.J.

Pathogen reduction: a precautionary principle 
paradigm. Transfusion Medicine Reviews, Orlando, v.22, n.2, p.97-102. 2008.

ANDRADE, João Marinho.

Funcções do fígado. Dissertação para obtenção do grau de Doutor - Faculdade de Medicina do Rio de Janeiro, Rio de Janeiro. 1883.

ANDRADE, Márcio Magalhães.

Proposta para um resgate historiográfico: as fontes do SESP/FSESP no estudo das campanhas de imunização no Brasil. História, Ciências, Saúde - Manguinhos, Rio de Janeiro, v.10, supl.2, p.843-848. 2003.

BARBOSA, Lincon de Paula.

Do diagnostico das causas mais communs da ictericia chronica. Dissertação para obtenção do grau de Doutor em Medicina - Faculdade de Medicina do Rio de Janeiro, Rio de Janeiro. 1915.

BARBOSA, Mario Monteiro Alves.

Das ictericias dissociadas e sua pathogenia. Dissertação para obtenção do grau de Doutor em Medicina - Faculdade de Medicina do Rio de Janeiro, Rio de Janeiro. 1921.

BARRETO, Joaquim Manhans.

A hepatite. Dissertação para obtenção do grau de Doutor em Medicina - Faculdade de Medicina do Rio de Janeiro, Rio de Janeiro. 1837.

BENCHIMOL, Jaime Larry (Coord.).

Febre amarela: a doença e a vacina, uma história inacabada. Rio de Janeiro: Editora Fiocruz. 2001.

CHALMERS, Thomas C. et al.

The treatment of acute infectious hepatitis: controlled studies of the effects of diet, rest, and physical reconditioning of the acute course of the disease and on the incidence of relapses and residual abnormalities. Journal of Clinical Investigation, New York, v.34, p.1163-1235. 1955.

CHOO, Qui-Lim et al.

Isolation of a cDNA clone derived from a blood-borne non-A, non-B viral hepatitis genome. Science, Washington, New Series, v.244, n.4902, p.359-362. Apr. 21, 1989.

COELHO, Henrique Sérgio Moraes.

Detecção de anticorpos contra o vírus da hepatite C na prevenção da infecção pós-transfusional pelo vírus da hepatite $C$. Tese (Doutorado) Faculdade de Medicina, Universidade Federal do Rio de Janeiro, Rio de Janeiro. 1998.

COELHO, Henrique Sérgio Moraes.

Hepatites crônicas: diagnóstico e tratamento estudo de 40 casos. Dissertação (Mestrado) -
Faculdade de Medicina, Universidade Federal do Rio de Janeiro, Rio de Janeiro. 1981.

EPPINGER, Hans.

Enfermedades del higado: patologia general y especial y tratamiento de las hepatopatias. Buenos Aires: Editorial Labor. 1940.

EQUI, Cláudia Maria de Andrade.

Estudo da incidência e dos fatores de risco nas hepatites por vírus $B$ e $C$ nos pacientes em tratamento de hemodiálise no HUCFF/UFRJ. Dissertação (Mestrado) - Faculdade de Medicina, Universidade Federal do Rio de Janeiro, Rio de Janeiro. 1995.

ESPÍRITO SANTO, Adriana Amaral; JACÓVILELA, Ana Maria; FERRERI, Marcelo de Almeida.

A imagem da infância nas teses da Faculdade de Medicina do Rio de Janeiro (1832-1930). Psicologia em Estudo, Maringá, v.11, n.1, p.19-28. 2006.

ESTRADA, Mario Duque.

Subsídio ao estudo das icterícias. Dissertação para obtenção do grau de Doutor em Medicina Faculdade de Medicina do Rio de Janeiro, Rio de Janeiro. 1927.

FAVERO, Maria de Lourdes de A.

Universidade do Brasil: das origens à construção. Rio de Janeiro: Editora UFRJ. 2000.

FERREIRA, Adriano.

Algumas reflexões sobre a hepatite aguda.

Dissertação para obtenção do grau de Doutor em Medicina - Faculdade de Medicina do Rio de Janeiro, Rio de Janeiro.1843.

FONSECA, Maria Rachel Fróes.

Fontes para a história das ciências da saúde no Brasil (1808-1930). História, Ciências, Saúde Manguinhos, Rio de Janeiro, v.9, supl., p.275288. 2002.

FONSECA, Maria Rachel Fróes.

Guia de fontes para a história do ensino médico no Rio de Janeiro (1808-1907). História, Ciências, Saúde - Manguinhos, Rio de Janeiro, v.2, n.1, p.126-128. 1995.

FRAGA FILHO, Clementino. Hepatite por vírus. Tese de Concurso Docente Faculdade de Medicina da Universidade do Brasil, Rio de Janeiro. 1952.

GAZE, Rosangela; CARVALHO, Diana Maul; TURA, Luiz Fernando Rangel.

Information from teachers on viral hepatitis transmission and prevention in Brazil. Salud Pública de México, México,v.45, n.4, p.245-251. 2003. 
GOMES, Augusto da Costa.

Da ictericia. Dissertação para obtenção do grau de Doutor em Medicina - Faculdade de Medicina do Rio de Janeiro, Rio de Janeiro. 1883.

GONÇALVES, Antonio Luiz Chaves. Enfoque epidemiológico da prevalência dos marcadores séricos do vírus da hepatite tipo $\mathrm{B} \mathrm{em}$ doadores de sangue: análise situacional dos aspectos encontrados. Dissertação (Mestrado) Faculdade de Medicina, Universidade Federal do Rio de Janeiro, Rio de Janeiro. 1987.

GUADAGNI, Emilio.

A cirrhose do fígado. [Tese] Validação de diploma da Universidade de Nápoles Faculdade de Medicina do Rio de Janeiro, Rio de Janeiro. 1863.

GUIMARÃES, Francisco Pinheiro.

Funcções do fígado. Tese de concurso docente Faculdade de Medicina do Rio de Janeiro, Rio de Janeiro. 1871.

\section{INFECTIVE HEPATITIS.}

Section of General Medicine of Scientific Discussions on International Conference of Physicians. Lord Moran, London, Sept. 11, 1947. Lancet, v.250, n.6473, p.435-436. Sept. 20, 1947.

\section{JAUNDICE FOLLOWING...}

Jaundice following yellow fever vaccination [Editorials]. Journal of the American Medical Association, Chicago, v.119, n.14, p.1110. Aug. 1, 1942.

LAGES JÚNIOR, Nuno Teixeira.

Do diagnostico das molestias do figado e seu tratamento. Dissertação para obtenção do grau de Doutor em Medicina - Faculdade de Medicina do Rio de Janeiro, Rio de Janeiro.1874.

LIMA, José Augusto de Oliveira.

Diagnostico da causas mais communs de ictericia chronica. Dissertação para obtenção do grau de Doutor em Medicina - Faculdade de Medicina do Rio de Janeiro, Rio de Janeiro. 1911.

\section{LÜRMAN, August.}

Eine Icterusepidemie. Berliner klinische Wochenschrift, Berlin, v.22, n.2, p.20-23. 12. Jan. 1885.

MACCALLUM, F.O.

Early studies of viral hepatitis. British Medical Bulletin, London, v.28, n.2, p.105-108. 1972.

MACHADO, Arthur Carneiro da Cruz. Da icterícia. Dissertação para obtenção do grau de Doutor em Medicina - Faculdade de Medicina do Rio de Janeiro, Rio de Janeiro. 1881.
MAGALHÃES, Fernando.

O centenário da Faculdade de Medicina do Rio de Janeiro. Rio de Janeiro: Barthel. 1932.

MAIA, Elias da Silva.

A construção do ensino médico no Rio de Janeiro no Brasil Império. Dissertação (Mestrado) Instituto de Estudos em Saúde Coletiva, Universidade Federal do Rio de Janeiro, Rio de Janeiro. 2010.

MAIA, Elias da Silva; CARVALHO, Diana Maul. Memória da Faculdade de Medicina do Rio de Janeiro: a proposta do Museu Virtual. Anais do Museu Histórico Nacional, Rio de Janeiro, v.40, p.519-533. 2008.

MATTOSO, Francisco de Queirós Carneiro. Estudo da hepatite suppurada. Dissertação para obtenção do grau de Doutor em Medicina Faculdade de Medicina do Rio de Janeiro, Rio de Janeiro. 1891.

MEYER, Sebastião.

Do diagnostico das causas mais communs da ictericia chronica. Dissertação para obtenção do grau de Doutor em Medicina - Faculdade de Medicina do Rio de Janeiro, Rio de Janeiro. 1913.

MIRANDA, Alcides da Rocha.

A reacção de triboulet no diagnostico da insuficiencia hepática. Dissertação para obtenção do grau de Doutor em Medicina Faculdade de Medicina do Rio de Janeiro, Rio de Janeiro. 1910.

MORGADO, Anastácio Ferreira. Hepatite transmitida por gamaglobulina. Dissertação (Mestrado) - Faculdade de Medicina, Universidade Federal do Rio de Janeiro, Rio de Janeiro. 1975.

OLIVEIRA, Alberto Miranda Baptista. A nova concepção da icterícia. Dissertação para obtenção do grau de Doutor em Medicina Faculdade de Medicina do Rio de Janeiro, Rio de Janeiro. 1920.

PEREIRA, Francisco Lafayette Rodrigues. Estudo clínico do cancer hepático. Dissertação para obtenção do grau de Doutor em Medicina - Faculdade de Medicina do Rio de Janeiro, Rio de Janeiro. 1916.

PIMENTEL, Alessandra.

O método da análise documental: seu uso numa pesquisa historiográfica. Cadernos de Pesquisa, São Paulo, n.114, p.179-195. 2001.

QUEIROZ JÚNIOR, José Narciso Dias Teixeira. Hepatites suppuradas. Dissertação para obtenção do grau de Doutor em Medicina Faculdade de Medicina do Rio de Janeiro, Rio de Janeiro. 1901. 
RONCAGLIO, Cynthia; NEUERT, Márcia; MARTINS, Maria da Aparecida Borges. Apontamentos para uma história da saúde: as fontes documentais do Paraná. História, Ciências, Saúde - Manguinhos, Rio de Janeiro, v.8, n.1, p.223-235. 2001.

SANTOS FILHO, Lycurgo.

História geral da medicina brasileira. São Paulo: Hucitec. 1991.

SILVA SOBRINHO, Antonio Moreira da Silva. Hepatite aguda. Dissertação para obtenção do grau de Doutor em Medicina - Faculdade de Medicina do Rio de Janeiro, Rio de Janeiro. 1881.

SOPER, Fred L.; SMITH, Hugh H. Yellow fever vaccination with cultivated vírus and immune and hyperimmune serum.
American Journal of Tropical Medicine, Baltimore, v.18, n.2, p.111-134. 1938.

UFRJ.

Universidade Federal do Rio de Janeiro. Base Minerva: Sistema de Documentação da Universidade Federal do Rio de Janeiro. Disponível em: www.minerva.ufrj.br. Acesso em: 31 out. 2010. s.d.

VIRCHOW, Rudolf.

La pathologie cellulaire: basée sur l'etude physiologique et pathologique des tissus. Trad. française faite sous les yeux de l'auteur par le Dr. Paul Picard, par le Dr. I. Straus. 4. ed. rev., corr. complétée, en conformité avec la 3. ed. allemande. Paris: J.B. Baillière et Fils. 1874. 